\title{
Current Academic Satisfactions and Problems of Chinese Students Participating in Higher Education in the UK*
}

\author{
Ruishu Wang \\ School of Humanities and Law \\ Northeastern University \\ Shenyang, China
}

\author{
Wanbing Shi \\ School of Humanities and Law \\ Northeastern University \\ Shenyang, China
}

\begin{abstract}
There has been an increase in the number of Chinese students who study abroad for higher education in the UK and Chinese students have already become the largest group of international students of the higher education in the UK. Thus, it is vital to evaluate the current academic satisfaction and problems of Chinese students learning experiences in the UK in order to promote Chinese students to notice an improvement and better achieve their education goals. The study investigated the academic satisfaction and problems of Chinese students participating in the higher education in the UK by adopting the mixed approach of quantitative and qualitative research, with 200 questionnaires and the semi-structured interviews of 6 participants with different educational background level. It covered Chinese students' satisfaction of quality of teaching, the accessibility of lectures and language adoption of participating in higher education in the UK and problems in the experiences of learning in the UK. The findings revealed that language adaption and accessibility of lectures were the major unsatisfied parts of Chinese students and language difficulties and not adapted to the UK's education system were the main problems of Chinese students learning in the UK. Furthermore, educational background level of Chinese appeared to be factor in evaluating the academic satisfaction learning experiences in the UK. It was found that PhD students were more satisfied with it than B.A and M.A students. The main problems of B.A and M.A students were the limited language skills and having difficulties in adapting to the UK education system, respectively.
\end{abstract}

Keywords-academic satisfaction; problems; Chinese students learning in the UK; different educational background level

\section{INTRODUCTION}

Since the "open-door" policy of China was introduced in 1978, the interactions between China and other countries has bulked up rapidly as increasingly Chinese students have selected to undergo the new culture and participant in higher education in outside world (Chiu, 1995).[1] According to the statistics from the Department of Education in China in "Fig. 1 ", in the recent two years during 2016 and 2017, there were 54,4500 Chinese students who studied abroad for higher education and they have already become the largest group in the world who select to participant in higher education as international students. Over $90 \%$ of these students chose to go to the America, the United Kingdom, Canada and Australia for further higher education.[2] Statistics from the Ministry of Education in the UK indicate that Chinese students have already become the largest group of international students in the UK. According to the data statistics from 2011 to 2017 of the Ministry of Education in China, the number of Chinese students who participant in higher education in the UK has been growing rapidly. According to the data statistics during 2011 and 2012, the number of Chinese students studying in the UK for higher education has reached 72072 while the number has risen to 87895 during 2013 to 2014. According to the newest data statistics during 2016-2017, the number of Chinese students studying in the UK for higher education has reached 95090 as shown in "Table I". [2] As illustrated in "Fig. 2", there has been an increasingly number of Chinese students who have chosen to study in the UK for higher education in recent years. Thus, the evaluation of current academic satisfaction and problems of Chinese students learning in the UK becomes vital since it could promote Chinese students learning in the UK to notice an improvement for better adapting the education in the UK. This study aims to investigate the current academic satisfaction and problems of Chinese students by questionnaire and semi-structured interview, regarding the quality of teaching, the accessibility of lectures as well as language adoption of participating in higher education in the UK and problems in the experiences of learning in the UK in order to provide some advice for further improvement.

*Fund Project: Research result of Northeastern University postgraduate education and scientific foundation project "Research on Postgraduate Funding System of Northeastern University" 


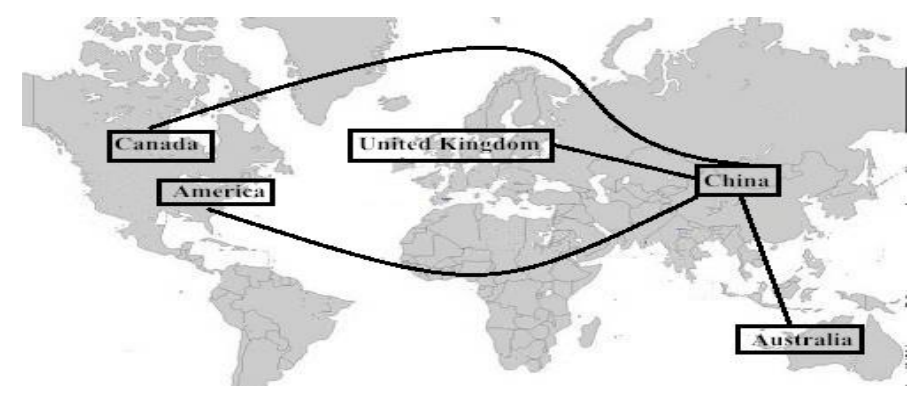

a. Data Source: from the website of Department of Education in China: http://www.moe.gov.cn/

Fig. 1. Distribution of overseas Chinese students during 2016-2017.

TABLE I. LIST Grownth in Total Number of Chinese StUdents Participating IN Higher Education in the UK

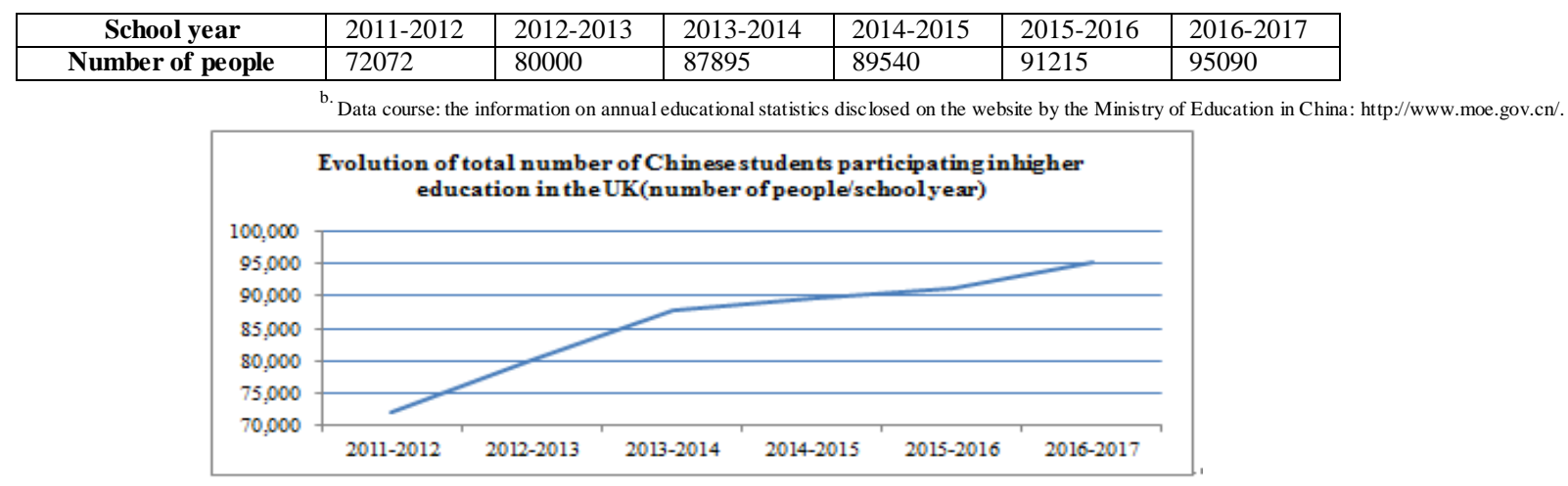

c. Data course: the information on annual educational statistics disclosed on the website by the Ministry of Education in China: http://www.moe.gov.cn/

Fig. 2. Growth of number of Chinese students participating in higher education in the UK.

\section{METHOD}

The research is based on an exploratory study to investigate current Chinese students' academic satisfaction and problems of studying in the UK and to ascertain aspects need to be improved. Data statistics for this research are from a questionnaire survey and semi-structured interviews of Chinese students at a public university in southwestern UK. 200 Chinese students with different educational background level received the questionnaire by email and 96 responded: a response rate of $48 \%$. The participants' demographic data are illustrated in Table II. Furthermore, six participants with different educational background level were randomly selected to be interviewed with the equal numbers of B.A (2), M.A (2) and PhD (2).

\section{A. Research Objectives}

The first objective of the study was to investigate the experiences of Chinese students on their learning experiences in relation to quality of teaching, students' accessibility of lectures, and language adaptation to evaluate the levels of their academic satisfaction by questionnaire. The second aim of the research was to figure out the current academic problems of Chinese students participating in higher education in the UK and promote to notice an improvement.

\section{B. Paticipants}

For the survey section, as shown in Table II, about half (48.5\%) of the respondents were 21-25 years of age while the participants of 18-20 years of age and 26-30 years of age accounted for $26 \%$ and $18 \%$ of the respondents respectively. B.A. accounted for $34 \%$ of the respondents $(n=68)$, M.A. represented $42 \%$ of the population $(\mathrm{n}=84)$ and $\mathrm{PhD}$ accounted for $24 \%$ of the participants $(n=48)$. For the semistructured interviews, six participants with different educational background level were randomly elected to be interviewed by telephone calls with the equal numbers of B.A (2), M.A (2) and PhD (2).

\section{Research Tools}

The questionnaire was pilot tested with several Chinese students with different educational background level and some revisions were made on the basis of these students' feedback. The questionnaire involved several questions about the level of Chinese students' satisfaction of quality of teaching, accessibility of lectures as well as language adaptation of participating in higher education in the UK. In the semi-structured interview section, participants were asked to respond to several questions about their current problems of the learning experience in the UK. All information collected during the course of the research will be kept strictly confidential. 


\section{Data Analysis}

Descriptive analyses were aim at setting up the overview of the level of Chinese students' academic satisfaction by listing percentages or displaying data by charts or tables. Then, inferential analyses were utilized in this study as it was effective for using data acquired from a small sample to make some judgments about a larger group (Kumar 2005).[3]
Content analysis, a device of comparing transcripts and identifying the main ideas and subjects from the response of respondents was used in the study as well to analyze the specific data in relation to Chinese students' academic problems and how different three groups of respondents' current situation compared with each other. Additional details of data are presented in the following section in "Table II" and "Fig. 3".

TABLE II. DEMOGRAPHIC DATA OBTAINED FROM SUVERY PARTICIPANTS

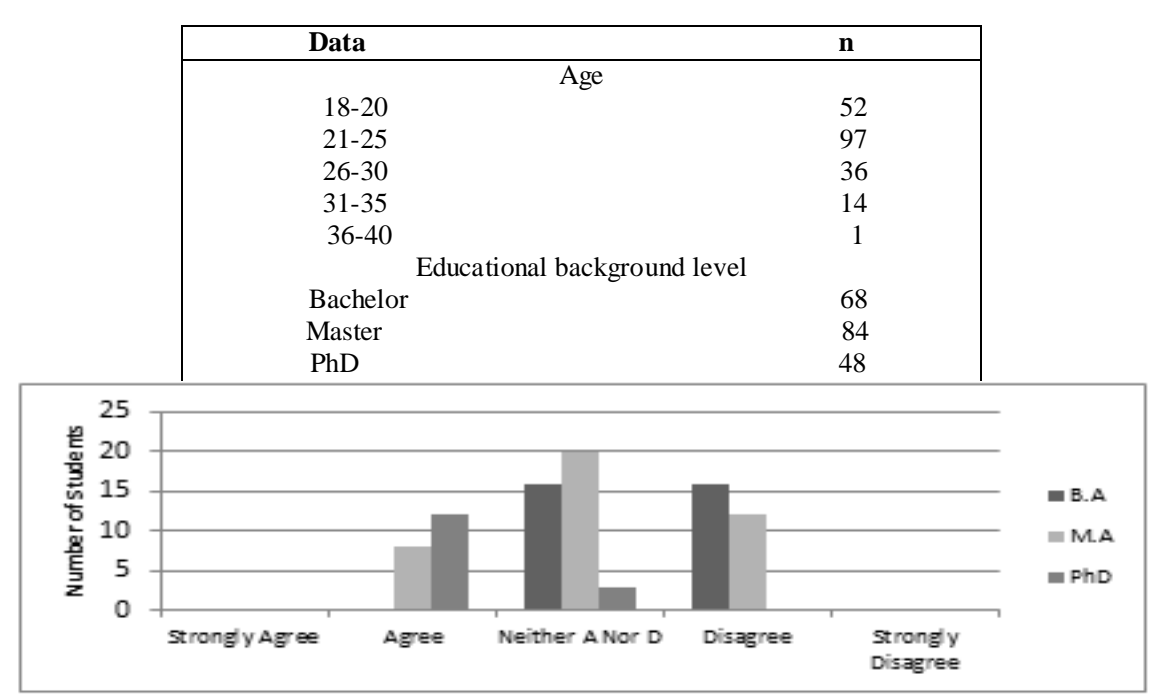

Fig. 3. Detailed responses of three different groups' participants to the question of satisfaction of the accessibility of lectures.

\section{E. Limitations}

The small sample in this study might not represent the population very well since Guthire states that "the bigger the sample, the better it will usually represent the population" (2010, p. 55). [4] Also, the response rate was only $48 \%$ in this study but according to Sodowsky and Carey (1988), sometimes it is common to have a low response rate especially with large population.[5]

\section{FINDINGS}

The data statistics was sorted out by the tabulation of percentage of responses of each option, listed by educational background levels and tabulated by the responses types. An additional qualitative analysis was done across the interview responses of the participants.

\section{A. The Level of Chinese Students'Academic Satisfaction of Higher Education In the UK}

Participants were asked to respond to three sections of statements on a Likert-type scale to evaluate the levels of satisfaction about their learning experiences, such as the quality of teaching, the accessibility of lectures and the language adaption during the education in the UK. Each of five-point response scales ranged from 1 ('strongly disagree') to 5 ('strongly agree'). Students generally agreed that they were satisfied the quality of teaching. Only $4.16 \%$ participants were slightly less positive about the satisfaction of teaching quality. With regard to the accessibility of lectures, majority participants believed that course content in the lectures was not easy to be followed. Only $20.83 \%$ respondents claimed that they could catch up their course content during the lectures. Furthermore, as shown in Fig three, all of the B.A students believed that it is not easy for them to follow the lectures while PhD participants felt much better about their accessibility of the course.

Language adaption was the most unsatisfied part of Chinese students participating in the higher education in the UK. Among the $79.17 \%$ who claimed that they had trouble catching up with the lectures, almost two-third (66\%) reported it as because of difficulty with language. Most of these participants believed that it was really necessary to have at least 2-3 months of English tuition before staring the study in the UK. Despite students' level of listening skills, written English was the most important but unsatisfied part of their language skills as most of them reported that it was hard to write academic paper without good written English skills which was also the hardest aspect of their academic learning experiences.

\section{B. The Current Problems of Chinese Students' Learning Experiences of Higher Education in the UK}

1) Language difficulties: A dominant problem of Chinese students participating in the higher education in the UK was that of difficulty with language. Most of the interviewees believed that they had failed to catch up the lectures because of their limited language skills. It was 
found that there was a mismatch between the language used by academic and the ability of some students.

"Sometimes I don't know what teachers are saying since my listening skill is too limited to follow their fast speaking pace. Sometimes since I don't know the meaning of key words on PowerPoint, the whole section of that point is difficult to be caught up which makes me have problem in following the next part of lecture." (Respondent A, B.A student)

Another B.A participant provided the similar comments with respondent $\mathrm{A}$ which would not be quoted here again.

"After I come to the UK, I find that good written English skill is really necessary for academic paper. Sometimes I have plenty of good ideas for the assignment but I could not express them well in written English which makes me feel really upset. It is necessary for Chinese students to have English tuition before they study in the UK which will benefit for them to achieve their academic goals." (Respondent B, M.A student)

Another M.A and $\mathrm{PhD}$ participants offered the similar comments with respondent $\mathrm{B}$ which would not be quoted here again.

2) Not adapted to the education system of the higher education in the UK: Another related and important theme for current problems of Chinese students leaning in the UK was that of not adapted to the education system in the UK. Most of the participants claimed that they could not adapt the new education system or method in a short time which somewhat caused their limited accessibility of lectures and academic learning in the UK.

"The education system is totally different between China and the UK. Also, the requirement of being in Master Level is different as well. Since I am an international student, everything is changed now. I need to adapt the new teaching methods, leaning approaches, rules and requirements in the UK as soon as possible which are not easy. Thus it might be hard for me to catch the Master level in a short time." (Respondent B, M.A student)

'UK's teachers focus more on students' ability of autonomous learning. Usually when teachers introduce a question in the lecture, firstly they would encourage students to discuss the topic in groups and try to get the answer. After that the ideas of all groups would be gathered and discussed with all members in the lecture. During the process, teachers would lead students to figure out the correct answer of the question. However, when I study in China, usually the teachers would directly tell students the answer which does not need students' ability of autonomous learning and thinking. Thus, at the very beginning of the experience of studying in the UK, I did not adapt education method in the UK which made me could not follow the lecture well. But now I am trying the best to adapt the education system here in order to achieve my education goals." (Respondent C, M.A student)

\section{CONCLUSION}

\section{A. The Reason Why Students Were not Satisfied}

As shown in results section, the accessibility of lectures and language adaptation were the two main aspects which Chinese students were not that satisfied. In terms of the academic dissatisfaction of accessibility of lectures, one of the reasons might be that some B.A and M.A students' academic and language skills are limited, thus, some lectures are hard to be followed for them. The responses from two B.A and one M.A. participants clearly made this point during the interviews. Another reason might be that the education system in the UK is totally different and not easy for Chinese students to adapt in a short time. Also, the lack of autonomous learning and thinking ability might cause the problems of their accessibility of lectures. Meanwhile, most of the students believed that language difficulty was center reason that directly affected their lectures' accessibility and achieving their education goals.

\section{B. A Versus M.A Versus PhD Students}

Educational background level appeared to be a factor in the responses to some questions, especially in the section of accessibility of lectures. In the question of academic satisfaction of accessibility of lectures, $\mathrm{PhD}$ students were more satisfied with it than B.A and M.A students. As a direct result, compared with PhD students, B.A and M.A students suffered more stress with language difficulties and they did have more problems of English skills. As English is the second language for Chinese students, sometimes it might be difficult for them to make sense of the key point and catch up the lectures with their limited academic ability. $\mathrm{PhD}$ students expressed higher levels of satisfaction with accessibility of lectures; it might be possible that the better English skills offered higher levels of learning experience satisfaction. However, the problems of B.A and M.A students were somewhat different. Some B.A students had limited language skills and academic ability while some M.A students had difficulties in adapting to the UK education system and catching up with Master level.

Thus, for Chinese B.A and M.A students who are studying or going to study in the UK for higher education, the first thing they need to do is to have English tuition to improve their language learning skills, especially English listening skills and written skills. And then they might need to go to library frequently to search and acquire more knowledge to improve their ability of academic, autonomous learning and thinking in order to follow the lectures better and achieve their further education goals.

\section{ACKNOWLEDGMENT}

My deepest gratitude goes to my supervisor Dr. Wanbing, Shi, for her constant encouragement and guidance. She has provided me with valuable guidance in every stage of the writing of this paper and developed my research ideas carefully, enthusiastically with encouragement and patient. Without her enlightening instruction and patience, this paper could not have reached its present form. Her devoted and 
vigorous academic observation and conscientious attitude enlighten me not only in this paper but also in my future study.

\section{REFERENCES}

[1] Chiu, M.L., 1995. The influence of anticipatory fear on foreign students adjustment: An exploratory study. International Journal of Intercultural Relations. 19, 1-44.

[2] http://www.moe.gov.cn/

[3] Kumar, Ranjit 2005, Research Methodology, Sage, London.

[4] Guthrie, Gerard. 2010. Basic Research Methods: An Entry to Social Science Research, Sage, India.

[5] Sodowsky, G.R, Carey, J.C., 1988. Relationship between acculturation related demographics and cultural attitudes of an AsianIndian immigrant group. Journal of Multicultural Counseling and Development. 16: 117-36. 